\title{
Service Philosophy Statements in Academic Libraries: A Qualitative Content Analysis
}

\author{
Paul Moffett \\ IUPUI University Library, Indiana University-Purdue University Indianapolis \\ Indianapolis, IN \\ and \\ William H. Weare, Jr. \\ Sterling C. Evans Library. Texas A\&M University \\ College Station, TX \\ Address correspondence to Paul Moffett pamoffet@iupui.edu
}

\begin{abstract}
Some academic libraries use service philosophy statements to strengthen the quality of their service culture. A service philosophy statement communicates directly to users what they can — and should — expect from the library. This article describes a study in which the authors applied qualitative content analysis to service philosophy statements. The objective was to examine the form and content of these statements and identify themes, trends, and ideas in order to determine how and what they communicate about a library's commitment to service. The results of the study found that statements in the sample varied significantly in strength and purpose.
\end{abstract}

\section{Keywords}

Academic libraries, content analysis, customer service, public services, service philosophy 


\section{Introduction}

While it is common for academic libraries to communicate mission, vision, values, and goals to users, these documents are not intended to convey the specific ways that service is delivered during everyday interactions with library staff. A service philosophy statement communicates to users what they can — and should — expect from the library.

In this study we ask how the form and content of a service philosophy statement communicates service expectations. We hope to better understand the impact that a service philosophy statement may have upon service quality at a public service desk. We will use qualitative content analysis to examine a sampling of service philosophy statements published on library websites of the Coalition of Urban and Metropolitan Universities (http://www.cumuonline.org/cumu-members/current-members/), an association with a broad variety of institutional types, to identify common themes, trends, and ideas.

\section{Definition: Service Philosophy Statements}

A service philosophy statement is a pledge to customers indicating the quality of service that can be expected. They are often used in retail, hospitality, and other organizations that provide service. Schmidt (2014) explains that for libraries, "this service philosophy should be a statement that explains a library's approach to service, and it should be valuable for both library staff and library members" (p. 21). These kinds of statements can appear under a variety of names, such as customer service principle or customer service pledge, but all communicate a similar message. A service philosophy statement is generally born of a customer service plan. Such a plan "includes the entire spectrum of customer service improvement efforts, such as the means to derive customer input and satisfaction (surveys, focus groups, etc.), staff customer-service training programs, and organizational response mechanisms" (Wehmeyer, Auchter, \& Hirshon, 1996, p. 173). A service philosophy statement publicly communicates those efforts as a promise or pledge. 
Service philosophy statements are different from commonly found library statements such as mission, vision, values, and goals. The library's mission statement generally supports the university's mission, while the vision, values, and goals reflect the library's mission. All tend to be aspirational and speak in general terms. Service philosophy statements, by contrast, are more specific. They speak directly to the user or customer about the way in which services and resources will be delivered, as shown in these two examples:

- We will communicate on the level of the customer — avoiding all jargon and explaining concepts clearly, and we will make services easily accessible.

- We will be alert and attentive as we move throughout the library, ready to offer assistance.

Another distinction between these types of statements is authorship. Mission, vision, values, and goals reflect the entire library's objectives, while service philosophy statements afford an opportunity for frontline service staff to communicate directly with users.

\section{Literature Review}

Service philosophy statements have not been examined extensively in the literature of library and information science. Some studies have applied content analysis to library mission statements, including those of ARL member academic libraries (Kuchi, 2006), California college and university library mission statements (Bangert, 1997a, 1997b), and public library mission statements (Barniskis, 2016). We found no comparable analyses of library service philosophy statements.

A number of academic libraries have developed and implemented customer service plans or programs, including, for example, Wright State University (Wehmeyer, Auchter, \& Hirshon, 1996), MIT (Helman \& Horowitz, 2001), and the University of Minnesota, Twin Cities (Bayer \& Llewellyn, 2011). Each recognized a service philosophy statement as a key 
component of these larger plans, and described the value of published statements for communicating a service commitment to users.

Several articles offered guidance as to how to craft a service philosophy statement and suggested elements that comprise a strong statement. Hirshon (1999) noted that a statement "often consists of two parts: a general pledge for service, followed by more specific and measurable objectives" (p. 67). Hirshon (1999) also listed several key factors in drafting a statement: include specific measures of performance, be brief and to the point, and "be specific, positive, emphatic, and use the active voice" (p. 69). He suggested that the statement be written from the perspective of the customer and avoid library jargon. Schmidt (2014) provided a short, four-point list of suggestions on developing a service philosophy: be inclusive, make it aspirational, keep it brief, and make it user focused. He concluded by emphasizing that "crafting a service philosophy is making a promise to your users. Even though your service philosophy will certainly impact the behavior of library workers, focus on communicating the benefits to your customers" (p. 21).

\section{Motivation}

Both authors of this study hold positions at our respective institutions in which we are responsible for the quality of customer service. Customer service has been satisfactory, but there is room for improvement. The experience of most customers varies depending on both what day they come in, the time of day, who they interact with, and the level of training of the staff member they encounter. We believe customers should have a more consistent experience.

One way to address this is to develop and publish a service philosophy statement. Service philosophy statements provide a vehicle for communicating a standard that may contribute to improved customer service. This is accomplished in several ways: the statements present clear expectations of service for users; they provide accountability, in that 
the library is held responsible for the services they claim to offer; and they provide staff a sense of the level of service they are in fact expected to supply. These factors help ensure that the quality of services are consistent across time and place.

Having already encountered examples of service philosophy statements used by retail, hospitality, and other service organizations including public libraries, we were interested in the potential for a service philosophy statement to improve quality at our public service desks. We looked for examples in academic libraries, and searched the literature for guidance on how we might construct our own. We examined the form and contents of these statements for common themes as well as strengths and weaknesses.

\section{Research Method}

To answer our research question, we analyzed a group of service philosophy statements using qualitative content analysis, a method of systematically describing and analyzing the meaning of qualitative data. Our process was largely guided by the method described by Schreier (2012), which incorporates developing a coding frame, segmenting data, and pilot testing, followed by analysis and presentation.

For our study, we chose to search for statements published on websites of member libraries of the Coalition of Urban and Metropolitan Universities (CUMU). We were familiar with CUMU because both authors worked at Indiana University-Purdue University Indianapolis (IUPUI), a member of the Coalition. Though we also considered other library associations, CUMU represents a diverse group of public and private colleges and universities, including community colleges, four-year colleges, and large universities offering a variety of graduate and professional degrees. Given that our study was exploratory, we intentionally selected a group of libraries with differing types, sizes, locations, and populations. 
We reviewed the library websites of all ninety member institutions. Fourteen (15.5\%) included language that informed library users about customer services that was not included in common statements such as mission, vision, values, and goals. Only eight (9\%) websites were selected for final examination, because they included language we identified as service philosophy. The eight were variously titled: Customer Service Principles of the University Library, User Conduct Guidelines, Customer Service Standards, Guiding Principles and Objectives, Customer Service Values, User Rights and Responsibilities, Users' Rights and Responsibilities, and Rules of the House. Regardless of name, they all share several distinguishing characteristics or themes.

The nature of these statements led us to believe that they should be easily findable. We found that, if available, they would be in one of several likely locations: co-located with mission, vision, values, and goals statements, or on pages that described library services or outlined library policies. We did not conduct exhaustive searches, nor did we contact the member libraries to confirm that no such statement existed.

We coded only the portion of text that appeared to be part of a service philosophy statement, usually a numbered or bulleted list; we did not code introductory text.

\section{The Coding Frame}

We identified two main categories for our coding frame—-form and content—-born out of our original research question. Form addresses the ways in which concepts contained in the statements are presented to users, while content describes the concepts communicated by the service philosophy statement.

Our initial coding frame included five sub-categories for form and six sub-categories for content. The sub-categories for form included author, grammatical person, intended audience, commissive modality, and presentation; the content sub-categories were courtesy, efficiency, effectiveness, continuous improvement, safety/security and dignity/respect. The 
sub-categories were derived in two ways. Initial sub-categories were identified based on what we expected to find, while additional sub-categories emerged during the pilot phase of the coding process. This reflects a distinction between concept-driven (inductive) and data-driven (deductive) category development.

We conducted a pilot using two customer service philosophy statements from our sample. Working together, we divided the statements into segments. A segment is a single sentence or phrase that represents a unique concept or idea within a statement. Each segment can be assigned to a single category. For example, "we strive to listen to your concerns and respond with appropriate action" was divided into two segments: "[we strive to] listen to your concerns" and "[we strive to] respond with appropriate action." Because we would be coding separately, it was imperative that we each code identical segments. Segmenting also allowed us to select only those parts of the data that helped answer our research question.

In qualitative content analysis, coders discuss the outcome in an effort to seek agreement as to how each segment is coded. When agreement between coders is high, the reliability of the coding frame is strengthened. Accordingly, after we finished coding the two pilot statements we discussed the segments that were coded differently, and established a shared understanding of how the remaining documents would be coded. With regard to form, we agreed on nine of the ten segmented portions. For content, thirty segments were coded, for which we agreed on twenty-one and disagreed on three. Following discussion, we reached agreement on those three segments. For the remaining six, we recognized that our original concept-driven sub-categories were insufficient for describing the content, as other concepts had emerged from the data that did not fit into the coding frame. The following six datadriven sub-categories were added: focus/priority, environment, accommodation, confidentiality, access, and attentive/listening. 
We then coded the entire set of documents independently. After completing the double-coding process, we met and discussed the segments that were coded differently and, as with the pilot stage, came to agreement about how those would be recoded.

\section{Results}

Results are reported using the same two main categories used in the coding frame, form and content.

\section{Form}

Each document was assigned a value for each of five concept-driven sub-categories denoting elements of form: author, grammatical person, intended audience, commissive modality, and presentation (see Table 1).

Table 1 Form sub-categories: description and frequency.

\begin{tabular}{|l|l|lc|}
\hline \multicolumn{1}{|c|}{ Sub-Categories } & \multicolumn{1}{|c|}{ Description } & \multicolumn{2}{c|}{ Coding frequency } \\
\hline \multirow{2}{*}{ Author } & Who wrote the statement? Who & Administration & 5 \\
& is making the commitment? & Multiple authors & 3 \\
\hline \multirow{2}{*}{ Grammatical Person } & Who is speaking? & First person plural & 4 \\
& & Third person plural & 4 \\
\hline Intended Audience & Who is the statement written & All & 8 \\
\cline { 2 - 3 } Commissive & What is the level of & Necessity & 3 \\
Modality & commitment? & Possibility & 1 \\
\hline \multirow{2}{*}{ Presentation } & Not present & 4 \\
\hline
\end{tabular}

The two most common similarities in form were found in the sub-categories presentation and intended audience. All but one of the statements was presented as a bulleted list. The audience was not identified by specific groups, such as faculty, staff, students, and community, but rather all of the statements addressed all users.

Variation occurred amongst the statements for authorship, commissive modality, and grammatical person. Concerning authorship, five of the eight statements appeared to be 
written from the perspective of the administration. The remaining three had no distinct point of view; authorship seemingly varied between administration and members of the public services staff.

Commissive modality refers to the level of commitment expressed by a speaker. J. L. Austin, a British philosopher of language who developed a taxonomy of illocutionary acts including commissives, wrote that "the whole point of a commissive is to commit the speaker to a certain course of action" (1962, p. 156). The words must, should, would, shall, and will indicate necessity, while may, might, can, and could indicate possibility. Three statements used necessity and one indicated possibility; four of the statements did not use the aforementioned terms. The three statements that did include necessity used the same commissive repeatedly, e.g., we will encourage, we will give, we will develop, etc.

Only two forms of grammatical person were found in the statements, first person plural and third person plural.

\section{Content}

The content of all eight documents was segmented into seventy-nine distinct units of coding, and each was assigned one of twelve possible sub-categories. We began this process by examining all seventy-nine segments collectively. Table 2 includes the descriptors used when assigning codes, as well as examples for each sub-category.

Schreier (2012) pointed out that in qualitative content analysis, "your coding frame itself may be your most important finding" (p. 219). This observation turned out to be significant for our study, because our original frame did not include all of the themes we discovered in the content. As described in the methods section, six new sub-categories emerged during the pilot coding. After the completion of coding, thirty-five of the seventynine segments were assigned to the new sub-categories. 
Table 2 Content sub-categories: descriptors and examples.

\begin{tabular}{|c|c|c|}
\hline Sub-Categories & Descriptors & Examples \\
\hline Courtesy & $\begin{array}{l}\text { Approachability } \\
\text { Demeanor } \\
\text { Friendliness } \\
\text { Welcoming } \\
\end{array}$ & $\begin{array}{l}\text { Our customers are shown courteous and } \\
\text { concerned attention }\end{array}$ \\
\hline Efficiency & $\begin{array}{l}\text { Promptness } \\
\text { Timeliness } \\
\text { Responsiveness } \\
\text { Flexibility } \\
\end{array}$ & $\begin{array}{l}\text { Library staff will acknowledge all } \\
\text { telephone, email, and in-person requests } \\
\text { in a timely manner }\end{array}$ \\
\hline Effectiveness & $\begin{array}{l}\text { Accuracy } \\
\text { Knowledgeability } \\
\text { Ability To Make Referral } \\
\text { Jargon-free Communication / } \\
\text { Non-Library Language } \\
\end{array}$ & $\begin{array}{l}\text { We will communicate on the level of the } \\
\text { customer - avoiding all jargon and } \\
\text { explaining concepts clearly }\end{array}$ \\
\hline $\begin{array}{l}\text { Continuous } \\
\text { Improvement }\end{array}$ & $\begin{array}{l}\text { Staff Training } \\
\text { Rewards / Reinforcement } \\
\text { Assessment }\end{array}$ & $\begin{array}{l}\text { We work with our co-workers, other } \\
\text { campus units, and community partners to } \\
\text { continuously improve resources, } \\
\text { processes, and services }\end{array}$ \\
\hline Safety / Security & & $\begin{array}{l}\text { Users may expect a library environment } \\
\text { that is welcoming, safe, and free of } \\
\text { disruptive activity }\end{array}$ \\
\hline Dignity / Respect & $\begin{array}{l}\text { Inclusiveness } \\
\text { Diversity }\end{array}$ & $\begin{array}{l}\text { The library will treat all customers in a } \\
\text { non-judgmental manner, with respect. . }\end{array}$ \\
\hline Focus / Priority & & $\begin{array}{l}\text { We ensure that our customers find value } \\
\text { in the services and knowledge resources } \\
\text { we provide by focusing our attention on } \\
\text { their research needs }\end{array}$ \\
\hline Environment & $\begin{array}{l}\text { Clean / Cleanliness } \\
\text { Comfort }\end{array}$ & $\begin{array}{l}\text { All users of the Libraries are entitled to a } \\
\text { clean physical environment }\end{array}$ \\
\hline Accommodation & $\begin{array}{l}\text { Special Populations } \\
\text { Special Needs } \\
\text { Disabilities } \\
\text { Accessibility } \\
\end{array}$ & $\begin{array}{l}\text { Library users have a right to expect } \\
\text { reasonable accommodation for } \\
\text { disabilities }\end{array}$ \\
\hline Confidentiality & $\begin{array}{l}\text { Privacy (of Records and } \\
\text { Personal Information) }\end{array}$ & $\begin{array}{l}\text { We will be reliable, accountable, and } \\
\text { have integrity in maintaining the } \\
\text { confidentiality of our customers }\end{array}$ \\
\hline Access & $\begin{array}{l}\text { Access to Services or } \\
\text { Resources }\end{array}$ & $\begin{array}{l}\text { We will provide our users with academic } \\
\text { information resources in the formats } \\
\text { most effective for instruction and } \\
\text { research }\end{array}$ \\
\hline Attentive / Listening & $\begin{array}{l}\text { Welcomes Feedback; } \\
\text { "We Hear You" }\end{array}$ & We strive to listen to your concerns \\
\hline
\end{tabular}


The two most frequently occurring sub-categories were efficiency and access. Other common themes included environment, courtesy, and effectiveness (see Figure 1).

Figure 1 Content: distribution of segments.

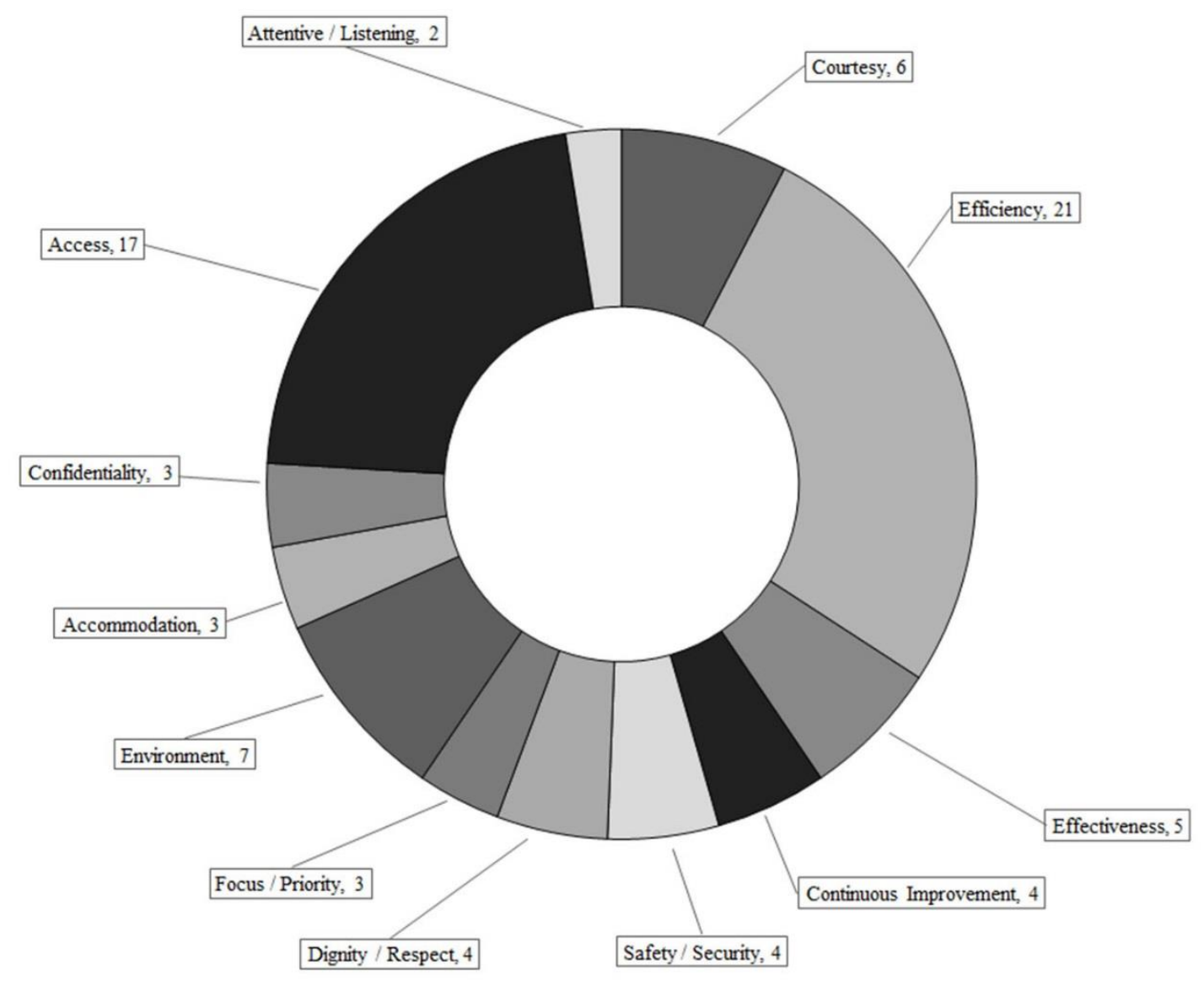

In some cases, individual statements were primarily focused on one particular aspect of service. In one statement, six of the seven segments were related to access. For another, ten of the eighteen segments addressed efficiency.

In addition to examining the distribution of the seventy-nine segments, we looked at the frequency with which each sub-category appeared across the eight statements. The most frequently appearing sub-categories were courtesy and access, each appearing in six of the eight statements. Both efficiency and environment were found in five of the statements (see Figure 2). On the other hand, only two libraries address focus/priority and attentive/listening. 
Statements from only three of the libraries reflected a broad spectrum of service concepts - i.e., the statements each included more than half of the sub-categories.

Figure 2 Content: appearance of sub-categories.

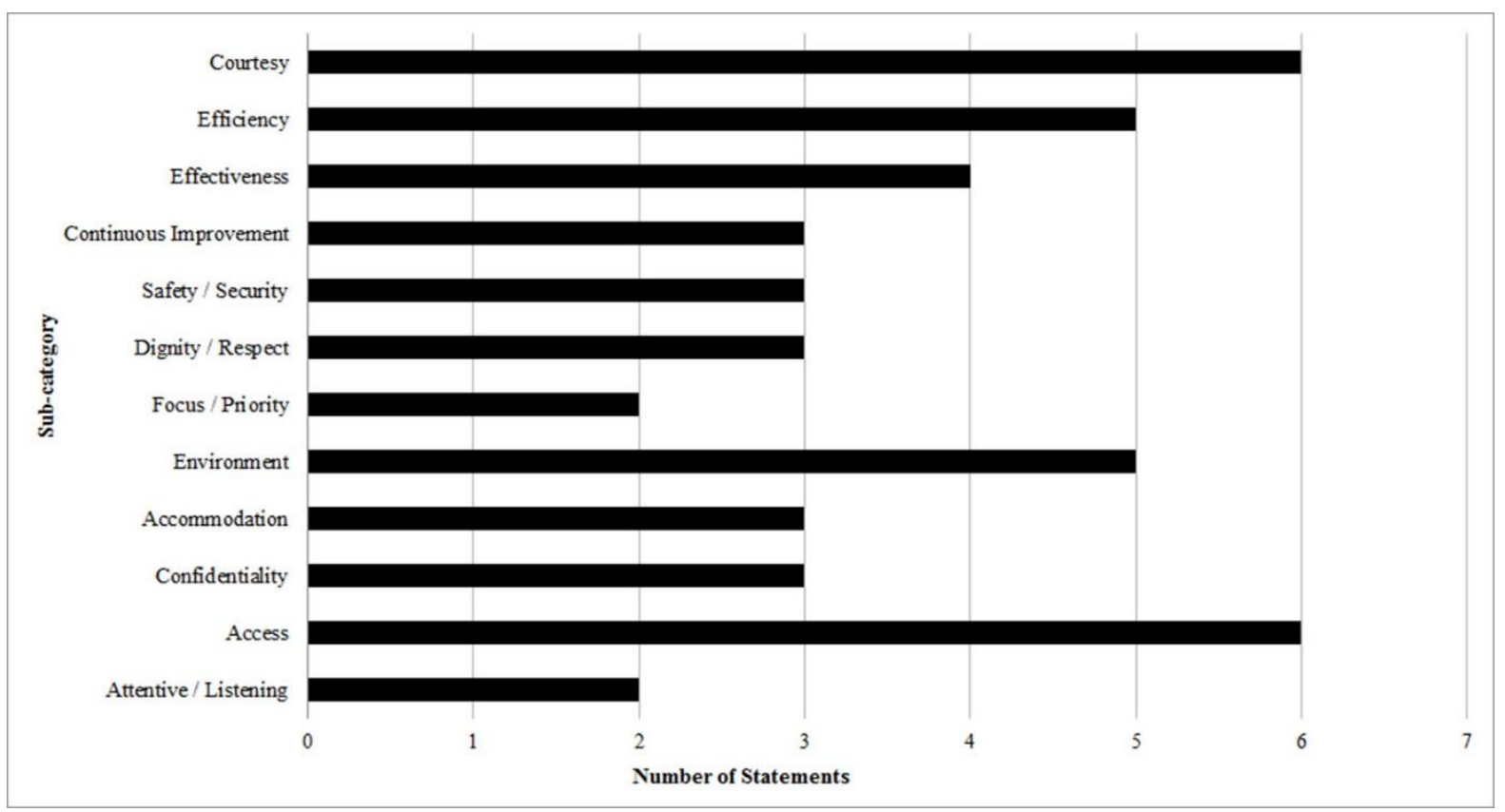

\section{Discussion}

We began this project with a number of expectations about service philosophy statements influenced by the literature and based on our exposure to examples found in librarianship, retail, hospitality, and other service organizations. While it's true that the examples which we examined were not specifically titled service philosophy statements, they were sufficiently alike in structure and language that we assumed commonalities would arise among the statements in terms of purpose, structure, and level of commitment. A discussion of our findings in terms of both form and content follows.

\section{Form}

The most common elements of form among the statements within our sample were presentation and intended audience; these elements most effectively communicated what the user may expect. Formatting as a bulleted list made statements more readable and accessible, 
in contrast to those composed in paragraph form. Secondly, seven of eight statements were addressed to all users rather than a specific group; this approach appeared more welcoming and inclusive.

Two other aspects of form — authorship and modality—were less effective. With regard to authorship, we had anticipated that these statements would have originated with frontline staff, the people who would be providing the service. Instead, we discovered that the prevailing voice appeared to come from library administration as if statements spoke for the whole organization or library. For example, "as a user-centered organization, we ensure that our customers find value in the services and knowledge resources we provide by focusing our attention on their research needs." These statements might have greater impact if the author is clearly identified as the individual delivering service; the $w e$ in the example that follows appears to be a staff member delivering the service: "We will be mobile in helping customers, providing seamless service whenever possible." Given the fact that these library websites already included multiple vehicles for the voice of administration to speak to users, such as mission, vision, values, and goals statements, statements specifically addressing service seemed an opportunity to speak from the perspective of the individuals delivering service.

We anticipated that the use of commissive modality-especially necessity (must, should, would, shall, and will)—would have appeared extensively in statements that are intended to deliver a promise. However, those statements without commissives did not offer a particularly convincing pledge. For example, "Our service-providers (staff, faculty, administrators, and student assistants) are knowledgeable about library services" is simply a statement about service, not a pledge to users. The primary reason for publishing service philosophy statements is to communicate to the user the institutional commitment to provide quality service. As Hirshon (1996) noted, “... it is important to establish a shared benchmark 
for the library staff and the customers to judge what constitutes quality service. To do this, the library must clearly articulate and publicize its service standards" (p. 7). We found that the statements that used words denoting necessity (commissive modality) expressed a stronger commitment, as in "library staff will acknowledge all telephone, email, and inperson requests in a timely manner."

\section{Content}

As expected, common themes addressing customer service such as courtesy, efficiency, and effectiveness were prevalent in the statements. However, the language used to describe the commitment to deliver them was often vague. For example, a statement such as "provide courteous service to every library user" does not identify specific attitudes or behaviors that model what courtesy could look like. If these statements were intended to be service philosophy statements, identifying behaviors such as a greeting, a smile, or eye contact would make the commitment more meaningful.

The efficiency and effectiveness themes followed a similar pattern, with non-specific language leaving the commitment to service undefined. For example, statements about efficiency suggested how staff would respond "in a timely manner" or would provide "timely responses." Statements addressing effectiveness also lacked specificity, although there were some better examples; one stated, "staff members will always research the question, followup and/or make an appropriate referral," while another suggested they communicate on the level of the customer, "avoiding all jargon and explaining concepts clearly." However, most statements addressing effectiveness avoided providing details about service delivery. Vague examples such as "courteous, efficient, and effective service in all circumstances and at all times" were more common.

As with courtesy, segments coded as efficiency or effectiveness might have more directly expressed consideration for users with language or details about how the service 
would be delivered. In the case of efficiency, a statement that promised a more definitive time frame, such as guaranteeing response to a complaint within twenty-four hours, would be more meaningful to the user. To illustrate effectiveness, a statement could have provided details about how staff will apply their research skills to provide accurate answers, or teach the user to find, evaluate, and use information. More specific examples would better convey to the user that library staff are committed to delivering quality service and better communicate what a user may expect.

A new data grouping emerged during the analysis of the content that was not contained in the coding frame; almost one third of the segments contained phrases that focused on features of the buildings or strengths of the collections. Emphasis on these aspects was not anticipated because we assumed more focus would be placed on services delivered by frontline public service staff. For example, one library communicated that users could expect "a clean physical environment," while another stated that users would find "library materials that are in good condition." While important, information about features of the buildings or strengths of the collections does not belong in a statement intended to communicate what users may expect in terms of quality service.

Likewise, some of the segments contained other information incongruent with service philosophy statements. Recall from the discussion of form—specifically of authorshipsome statements appeared to originate with administration. The content of these statements appeared to follow a similar pattern; they address concerns of administration by communicating library policy, goals, and values, rather than address service quality. For example, "library users have a right to expect confidential access to library resources" reads like a values statement. Another stated that "all users of the libraries are entitled to access to library resources" or access to "library materials that are in good condition." These 
sentiments express values that a user might expect of a library, however they are not services delivered by frontline staff.

Lastly, several segments included reference to staff development or recognition and did not directly express a service commitment to users. The sub-category continuous improvement contained segments such as "we will provide ongoing training to enable and enrich our staff" or "we will honor and recognize our employees for good customer service." Continuous improvement should be part of any employee development program but these examples did not specify how this would improve services for users.

\section{Conclusion}

Overall, these statements did not align with our expectations of how service philosophy statements should function, based on what we read in the literature as well as examples found outside of this sample group. Although there were ninety libraries in the population, only eight met our final criteria for review. The statements we examined were notable for the absence of language indicating explicit promises or commitment from staff regarding service delivery, such as commissive modality of necessity or authorship by frontline service providers. By including these elements, service philosophy statements are more likely to instill confidence in the user that the service will be delivered. Likewise, prevalent themes within the content were in most cases lacking enough specific information to identify a standard of quality for a given service. Additionally, a significant portion of the statements focused on buildings and collections, which as noted previously falls outside the notion of services deliverable by staff.

Based on our research, it appears that statements within the sample group communicated a variety of messages to users including policy, availability of amenities and services, or values and goals. We did not find clear consensus among how these statements were used or how their form or content communicated service expectations to users. 
This study provides a first step in examining how academic libraries communicate service expectations through the use of a service philosophy statement. Additional studies are needed in order to validate the results of the present work. Other study groups could include members of the Association of College \& Research Libraries or randomly sampled academic libraries from different Carnegie classifications. Alternatively, the study group could be drawn from institutions that share particular attributes such as members of the Association of Research Libraries.

Further opportunities for research include studies that explore the relationship between the use of a service philosophy statement and customer satisfaction or service quality. Based on our work, we are considering the development and implementation of a service plan and service philosophy statement at our respective institutions. 


\section{References}

Austin, J. L. (1962). How to do things with words. Cambridge, MA: Harvard University Press.

Bangert, S. R. (1997a). Thinking boldly! College and university library mission statements as roadsigns to the future. Paper presented at the 1997 ACRL National Conference, Nashville, TN. Retrieved from http://www.ala.org/acrl/publications/whitepapers/nashville/bangert

Bangert, S. R. (1997b). Values in college and university library mission statements: A search for distinctive beliefs, meaning, and organizational culture. Advances in Librarianship, 21, 91-106. doi:10.1108/S0065-2830(1997)0000021007

Barniskis, S. C. (2016). Deconstructing the mission: A critical content analysis of public library mission statements. Library Quarterly, 86, 135-152. doi:10.1086/685403

Bayer, J., \& Llewellyn, S. (2011). The customer comes first: Implementing a customer service program at the University of Minnesota, twin cities libraries. Journal of Access Services, 8, 157-189. doi:10.1080/15367967.2011.593419 doi:10.1086/685403

Helman, D., \& Horowitz, L. R. (2001). Focusing on the user for improved service quality. Science \& Technology Libraries, 19, 207-219. doi:10.1300/j122v19n03_14

Hirshon, A. (1996). Running with the Red Queen. Advances in Librarianship, 20, 1-26. doi:10.1108/S0065-2830(1996)0000020003

Hirshon, A. (1999). The development of library client service programs and the role of library corsortia. Library Consortium Management: An International Journal, 1, 5975. doi:10.1108/14662769910305759

Kuchi, T. (2006). Communicating mission: An analysis of academic library web sites. The Journal of Academic Librarianship, 32, 148-154. doi:10.1016/j.acalib.2005.12.006 
Schmidt, A. (2014). Developing a service philosophy. Library Journal, 139, 21.

Schreier, M. (2012). Qualitative content analysis in practice. Los Angeles: Sage.

Wehmeyer, S., Auchter, D., \& Hirshon, A. (1996). Saying what we will do, and doing what we say: Implementing a customer service plan. The Journal of Academic Librarianship, 22, 173-180. doi:10.1016/s0099-1333(96)90055-5 